\title{
Corpos estranhos animados em otorrinolaringologia
} Strange animated bodies in othorinolaringology

Ricardo R. Figueiredo ${ }^{1}$, Sandro Dorf ${ }^{2}$, Márcia S. Couri ${ }^{3}$, Andréia A. Azevedo ${ }^{4}$, Fernanda Mossumez 5

\section{Palavras-chave: corpos estranhos animados,} insetos, otorrinolaringologia.

Key words: strange animated bodies, insects, otolaryngology.

\section{Resumo / Summary}

orma de estudo: Clínico retrospectivo. Material e método: Foram reportados 56 casos de corpos estranhos animados em orelhas (55 insetos e 1 aracnídeo) e 1 caso (inseto) em fossas nasais. O material foi coletado no setor de Emergência do serviço de ORL do Hospital Municipal Souza Aguiar, no centro do Rio de Janeiro, entre os anos de 1998 e 2000, e identificado por zoólogos do Museu Nacional, Rio de Janeiro. A maior parte dos casos ocorreu em Nova Iguaçu e Campo Grande, sendo analisados os quadros clínicos e as complicações ocorridas. Resultado: Os insetos são: 30,35\% Blattaria (baratas); 25\% Diptera (moscas e mosquitos); $12,5 \%$ Lepidoptera (borboletas e mariposas); 10,7\% Coleoptera (besouros); 7,15\% Hemiptera (percevejos, cigarras, afídeos, etc.), 5,35\% Hymenoptera (vespas, abelhas, formigas, marimbondos) e 5,31\% outros.

\begin{abstract}
$\mathrm{S}$ tudy design: Clinical retrospective. Material and method: Fufty-six cases of animated foreign bodies collected inside human ears (55 insects and 1 arachnid) and one case collected in nasal fossae (insect) were reported. The material was collected in the Emergency sector of Souza Aguiar Hospital, in Rio de Janeiro, between 1998 and 2000, and was identified by zoologists of Museu Nacional, Rio de Janeiro. Most of the cases had occurred in Nova Iguaçu and Campo Grande, suburbs of Rio de Janeiro. Clinical features and complications were analyzed. Results: The recorded insects are: 30,35\% Blattaria (cockroaches); 25\% Diptera (flies and mosquitos); $12,5 \%$ Lepidoptera (butterflies and moths); 10,7\% Coleoptera (beetles); 7,15\% Hemiptera (bugs, cicads, aphids, etc.), 5,35\% Hymenoptera (wasps, bees, ants, and sawflies) and 5,31\% others.
\end{abstract}




\section{INTRODUÇÃO}

Diferentes tipos de organismos podem invadir o corpo humano de várias formas por via inalatória, ingestão de alimentos e água contaminados e contato sexual, ou seja, penetrando as cavidades naturais do corpo humano. As conseqüências podem variar, desde ligeiro desconforto até quadros clínicos graves, se forem eles patogênicos para o homem. A literatura reporta casos de lesões de cavidades e ulcerações, como infestação da mucosa oral, entre outras.

Algumas espécies de artrópodes podem invadir o corpo humano por orifícios naturais, principalmente boca, narinas e condutos auditivos externos. Insetos, tanto na forma adulta quanto jovem, são alguns desses invasores. Um exemplo de invasão humana por insetos é a miíase, que consiste na infestação por larvas de moscas em tecidos vivos ou mortos. As larvas podem causar vários tipos de danos, dependendo da espécie e das circunstâncias em volta da infestação, como as infecções bacterianas secundárias e o estado imunológico do paciente.

Em seres humanos, os ouvidos, nariz e garganta são as áreas mais comumente infestadas, e casos mortais têm sido relatados na literatura (Guimarães \& Papavero, 1999).

O objetivo desde estudo é identificar os principais invasores no estado do Rio de Janeiro, classificando-se e descrevendo as alterações clínicas por eles causadas, bem como a terapêutica, ajudando a prevenir quanto a futuras invasões.

\section{MATERIAL E MÉTODO}

O material estudado foi coletado no setor de Emergência do serviço de ORL do Hospital Municipal Souza Aguiar, no centro do Rio de Janeiro, durante os anos de 1998 a 2000. Consiste em 56 amostras de organismos

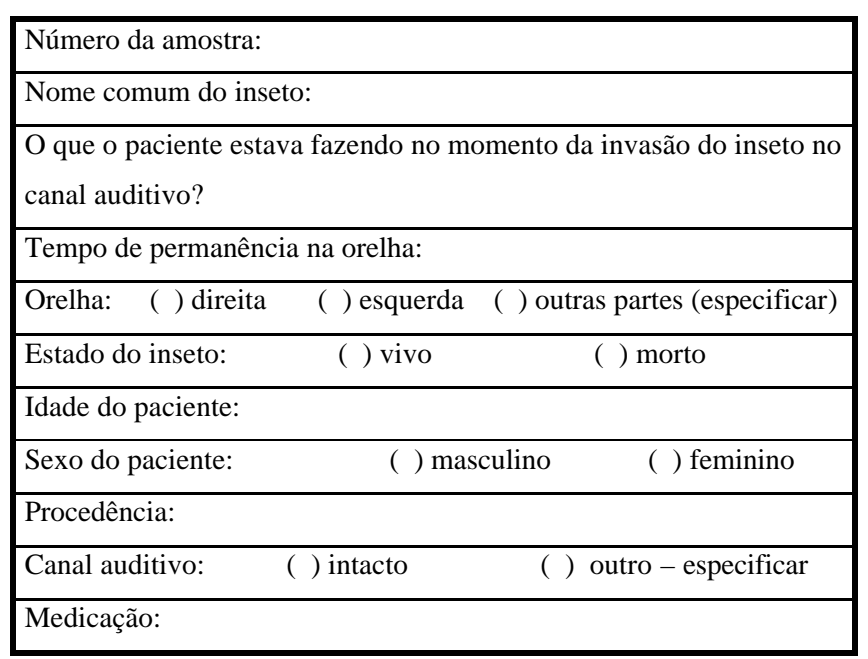

Figura 1. Formulário com os dados do paciente e do inseto invasores preservados em tubos de ensaio com formol. Para cada caso, foi preenchido um formulário, registrando informações, tais como: nome comum do inseto (atribuído pelo paciente ou equipe), atividade exercida pelo paciente no momento da invasão (deitado, andando, etc.), tempo decorrido desde a invasão e outros (Figura 1).

O material foi colhido através de lavagem otológica ou com o auxílio de pinças tipo Hartmann ou Jacaré, eventualmente, com auxílio de microscópio, após a verificação do estado do inseto (vivo ou morto). Quando vivos, eram previamente sacrificados através da instilação de éter, com exceção das larvas. Dadas as dificuldades técnicas da remoção em alguns casos, certas amostras encontravam-se extremamente danificadas, impossibilitando a identificação até o nível de espécie.

As informações sobre as amostras estão resumidas na Tabela 1, que também incluiu a identificação dos organismos, separados por Ordem. As identificações foram feitas por pesquisadores dos Departamentos de Entomologia e Invertebrados do Museu Nacional, Rio de Janeiro. Todo o material encontra-se depositado na coleção do Museu Nacional.

\section{RESULTADO E DISCUSSÃO}

\section{Aspectos Biológicos}

Todo o material examinado continha insetos, exceto as amostras 7 e 45, que continham aracnídeos. A maioria foi identificada até espécie ou gênero, alguns até família, tanto pela falta de especialistas naquele determinado grupo de insetos, quanto pelo estado da amostra. A identificação encontra-se na Tabela 1.

Os dados mostram que a maioria (cerca de 55,35\%) dos invasores consiste em Blattaria (baratas) ou Diptera (moscas e mosquitos), respectivamente responsáveis por $30,35 \%$ e $25 \%$ dos casos. A seguir, vêm Lepidoptera (borboletas e mariposas), 12,50\%; Coleoptera (besouros), 10,70\%; Hemiptera (percevejos, cigarras, etc.), 7,15\%; Hymenoptera (vespas, abelhas, formigas), 5,35\%; Isoptera (cupins) e Aranae (aranhas), 3,60\% e apenas 1,71\% são Thysanura.

Blattaria (Figuras 2-3) estão principalmente representadas por Periplan eta spp. (47,5\%) e Blatella spp. (29,5\%), que são espécies domésticas. Estas baratas procuram por restos de comida dentro das residências e podem ser responsáveis pela transmissão de doenças bacterianas e protozooses por contaminação de alimentos. Podem também invadir a mucosa labial das pessoas durante o sono, procurando por restos de comida, resultando em uma forma de herpes conhecida por "Herpes blattae" (Costa Lima,1938). Todas as espécies de Blatella eramB. germanica (Linnaeus). As outras espécies encontradas foram Pycnoscelus surinamensis (17\%) e Ischnoptera spp. (6\%). 
Tabela 1. Corpos estranhos animados em orelha de pacientes da Emergência do Hospital Souza Aguiar - identificação e informação sobre o paciente e o inseto

\begin{tabular}{|c|c|c|c|c|c|c|c|c|}
\hline $\begin{array}{l}\text { CORPO ANIMADO } \\
\text { Identificação (nr. da amostra) }\end{array}$ & $\begin{array}{l}\text { INFORMAÇÕES S } \\
\text { Procedência }\end{array}$ & $\begin{array}{l}\text { SOBRE O } \\
\text { Sexo do } \\
\text { paciente }\end{array}$ & $\begin{array}{l}\text { PACIENTE } \\
\text { Idade do } \\
\text { paciente }\end{array}$ & $\begin{array}{l}\text { E O INSETO } \\
\text { Tempo de } \\
\text { infestação (h: } \\
\text { horas; d:dias) }\end{array}$ & $\begin{array}{l}\text { Orelha } \\
\text { infestada }\end{array}$ & $\begin{array}{l}\text { Estado } \\
\text { do inseto }\end{array}$ & $\begin{array}{l}\text { O que a pessoa estava } \\
\text { fazendo no momento da } \\
\text { invasão }\end{array}$ & $\begin{array}{l}\text { Estado do canal } \\
\text { auditivo }\end{array}$ \\
\hline \multicolumn{9}{|l|}{ COLEOPTERA (besouros) } \\
\hline Geniates sp (4) & Realengo & M & 39 & $3 \mathrm{~h}$ & $\mathrm{E}$ & Morto & Em pé no quarto & Hyperemia \\
\hline Leucothyreus sp (8) & Nova Iguaçú & $\mathrm{F}$ & 8 & $14 \mathrm{~h}$ & $\mathrm{D}$ & Morto & Deitado na cama & Lacerado \\
\hline Leucothyreus sp (26) & Campo Grande & M & 28 & $4 \mathrm{~h}$ & $\mathrm{D}$ & Morto & No quintal & MT inflamada \\
\hline Cratomorphus giganteus (42) & Nova Iguaçú & $\mathrm{F}$ & 17 & $14 \mathrm{~h}$ & $\mathrm{D}$ & Morto & Deitado na cama & Hyperemia \\
\hline Onthophagus sp (48) & Majé & M & 43 & $24 \mathrm{~h}$ & $E$ & Morto & Próximo a uma floresta & Inflamado \\
\hline Eutheola humilis (53) & Nova Iguaçú & M & 45 & $8 \mathrm{~h}$ & D & Morto & No quintal & Lacerado \\
\hline \multicolumn{9}{|c|}{ HEMIPTERA (percevejos, cigarras, afídeos, etc) } \\
\hline Cimex hemipterus (29) & Mesquita & $\mathrm{F}$ & 35 & $5 \mathrm{~h}$ & $E$ & Morto & Deitado na cama & Intacto \\
\hline Polana tulara (52) & Tomás Coelho & $\mathrm{F}$ & 25 & $2 \mathrm{~h}$ & D & Vivo & Sentado fora de casa & Hyperemia \\
\hline Cydnidae (57) & Angra dos Reis & $\mathrm{F}$ & 9 & $14 \mathrm{~h}$ & $\mathrm{E}$ & Morto & Deitado na cama & Intacto \\
\hline Macyconalia cavifrons (60) & Majé & $\mathrm{F}$ & 6 & $3 \mathrm{~h}$ & D & Morto & Pedalando em volta de casa & Intacto \\
\hline \multicolumn{9}{|c|}{ LEPIDOPTERA (borboletas e mariposas) } \\
\hline Gelechiidae (03) & Costa Barros & M & 2 & $72 \mathrm{~h}$ & $\mathrm{E}$ & Morto & Deitado na cama & Intacto \\
\hline Pyralidae (06) & Inhaúma & M & 10 & $1 \mathrm{~h}$ & $\mathrm{E}$ & Morto & - & Intacto \\
\hline Noctuidae (11) & Inhaúma & M & 10 & $1 \mathrm{~h}$ & $\mathrm{E}$ & Morto & - & Intacto \\
\hline Pyralidae (32) & Fátima & M & 42 & $4 \mathrm{~h}$ & D & Morto & Na rua & Lacerado \\
\hline Carposinidae (43) & Nova Iguaçú & M & 45 & $16 \mathrm{~h}$ & $\mathrm{E}$ & Morto & Sentado na cama & Intacto \\
\hline Ardiosteres sp ( 51) & Nova Iguaçú & M & 51 & $2 \mathrm{~h}$ & D & Morto & Em pé na sala & Hyperemia \\
\hline Castniidae (54) & São J oão & M & 27 & $3 \mathrm{~h}$ & D & Vivo & Na rua & Intacto \\
\hline DIPTERA (moscas e mosquitos) & & & & & & & Seating in the bed & \\
\hline Cochliomyia macellaria (2) & Ilha & M & 41 & $4 \mathrm{~h}$ & D & Morto & No quintal, limpando peixe & Intacto \\
\hline Culex sp (9) & Realengo & $\mathrm{F}$ & 52 & $7 \mathrm{~h}$ & $\mathrm{E}$ & Morto & Sentado na cama & Intacto \\
\hline Cochliomyia hominivorax (10) & Ignored & M & 56 & $5 \mathrm{~h}$ & $\mathrm{D} / \mathrm{E}$ & Vivo & $\begin{array}{l}\text { Dormindo em prédios } \\
\text { em construção, mendigo }\end{array}$ & $\begin{array}{l}\text { Necrose e infeção } \\
\text { dos ossos turbinais }\end{array}$ \\
\hline Cochliomyia hominivorax (14) & \multicolumn{2}{|c|}{ Marquês de Barbacena } & M & 55 & $7 \mathrm{~h}$ & D & Vivo & Em um prédio Intacto \\
\hline Cochliomyia hominivorax (20) & Nova Iguaçú & $\mathrm{F}$ & 46 & $6 \mathrm{~h}$ & $E$ & Vivo & No quintal, lavando roupa & $\begin{array}{l}\text { MT perfurada e } \\
\text { infectada }\end{array}$ \\
\hline Cochliomyia hominivorax (25) & Belford Roxo & M & 1 & Ignorado & $\mathrm{E}$ & Vivo & Ignorado & Necrose e infeção \\
\hline Culex sp (27) & Vilar dos Teles & M & 6 & Ignorado & D & Vivo & Ignorado & $\begin{array}{l}\text { MT um pouco } \\
\text { inflamada }\end{array}$ \\
\hline Culex sp (28) & Campo Grande & M & 35 & $12 \mathrm{~h}$ & $\mathrm{D}$ & Vivo & Deitado na cama & Intacto \\
\hline Cochliomyia hominivorax (33) & Belford Roxo & M & 15 & $3 d$ & $E$ & Vivo & Na rua & $\begin{array}{l}\text { Necrose e infecção } \\
\text { MT não visível }\end{array}$ \\
\hline Culex sp (35) & São J oão de Miriti & $\mathrm{F}$ & 12 & $5 \mathrm{~h}$ & $\mathrm{E}$ & Morto & Dormindo na cama & Intacto \\
\hline Oxysarcodexia amorosa (36) & São J oão de Meriti & M & 39 & $11 \mathrm{~h}$ & $E$ & Morto & Trabalhando em um bar & Hyperemia/TM intacta \\
\hline $\begin{array}{l}\text { Cochliomyia hominivorax (47) } \\
\text { BLATTARIA (baratas) }\end{array}$ & Vila Valqueire & M & 17 & Ignorado & $\mathrm{D}$ & Vivo & Ignorado & Intacto \\
\hline Periplaneta sp (01) & Campo Grande & M & 59 & $5 \mathrm{~h}$ & $\mathrm{E}$ & Morto & Dormindo no chão & Hyperemia/TM intacta \\
\hline Periplaneta sp (08) & Santa Cruz & $\mathrm{F}$ & 22 & $7 \mathrm{~d}$ & D & Morto & Dormindo em casa & Lacerado \\
\hline Pycnoscelus surinamensis (12) & Bonsucesso & M & 28 & $3 \mathrm{~h}$ & D & Morto & $\mathrm{Na}$ floresta & Intacto \\
\hline Blattela germanica (15) & Glória & $\mathrm{F}$ & 61 & $2 \mathrm{~h}$ & D & Vivo & Deitado na cama & Intacta \\
\hline Blattela germanica (17) & Caxias & $\mathrm{F}$ & 3 & $2 \mathrm{~h}$ & $\mathrm{E}$ & Morto & Brincando no quarto & Hyperemia/TM intacta \\
\hline Blattela germanica (18) & Penha & $\mathrm{F}$ & 40 & $1 \mathrm{~h}$ & $\mathrm{E}$ & Vivo & Deitado na cama & Intacto \\
\hline Periplaneta sp (23) & Ilha do Governador & $\mathrm{F}$ & 25 & $2 d$ & $\mathrm{E}$ & Morto & Em pé no quarto & Hyperemia/TM intacta \\
\hline Blattela germanica (24) & Centro & $\mathrm{F}$ & 42 & $4 \mathrm{~h}$ & D & Vivo & Deitado na cama & Inflamado \\
\hline Periplaneta sp (31) & Nova Iguaçu & $\mathrm{F}$ & 18 & $18 \mathrm{~h}$ & D & Morto & Dormindo em casa & Intacto \\
\hline Periplaneta sp (37) & J acarepaguá & $\mathrm{F}$ & 7 & $24 \mathrm{~h}$ & $\mathrm{D}$ & Morto & Ignorado & Hyperemia/TM intacta \\
\hline Periplaneta sp (38) & Nova Iguaçú & M & 29 & $6 \mathrm{~h}$ & $\mathrm{D}$ & Morto & Dormindo em casa & Lacerado \\
\hline Periiplaneta sp (40) & Centro & $\mathrm{F}$ & 12 & $2 \mathrm{~h}$ & D & Vivo & Dormindo no chão & Intacto \\
\hline Blattela germanica (44) & Nova Iguaçú & $\mathrm{F}$ & 28 & $2 \mathrm{~h}$ & $E$ & Morto & Dormindo no chão & Hyperemia/TM intacta \\
\hline Ischnoptera sp (50) & Nilópolis & M & 9 & $4 \mathrm{~h}$ & D & Morto & Em pé perto de uma árvore & Intacto \\
\hline Pycnoscelus surinamensis (55) & Campo Grande & $\mathrm{F}$ & 14 & $3 \mathrm{~h}$ & $\mathrm{D}$ & Morto & Deitado no sofá & Intacto \\
\hline Pycnoscelus surinamensis (56) & Campo Grande & $\mathrm{F}$ & 32 & $4 \mathrm{~h}$ & $\mathrm{E}$ & Morto & Sentado em uma árvore & Intacto \\
\hline $\begin{array}{l}\text { Periplaneta sp ( } 58 \text { ) } \\
\text { HYMENOPTERA (vespas, abelha }\end{array}$ & & \multicolumn{7}{|c|}{ HYMENOPTERA (vespas, abelhas, formigas, etc) } \\
\hline Formicidae $(05)$ & Nova Iguaçú & M & 25 & $6 \mathrm{~h}$ & $\mathrm{D}$ & Morto & Em pé no quarto & Intacto \\
\hline Apidae (07) & Nova Iguaçú & $\mathrm{F}$ & 15 & Ignorado & D & Morto & Ignorado & Hyperemia;MT intacta \\
\hline Formicidae (49) & Illha do Governador & $\mathrm{F}$ & 50 & $12 \mathrm{~h}$ & D & Morto & Dormindo no chão & Intacto \\
\hline PSOCOPTERA (16) & Campo Grande & $\mathrm{F}$ & 29 & $4 \mathrm{~h}$ & $\mathrm{E}$ & Morto & Dormindo na cama & Intacto \\
\hline $\begin{array}{l}\text { EMBRIOPTERA (39) } \\
\text { ISOPTERA (térmitas) }\end{array}$ & Campo Grande & $\mathrm{F}$ & 40 & $5 \mathrm{~h}$ & $E$ & Morto & No quintal tomando café & Intacto \\
\hline Captotermes havelandi (34) & Irajá & M & 10 & $12 \mathrm{~h}$ & D & Morto & Deitado na cama & Intacto \\
\hline Captotermes havelandi (59) & Nova Igraçú & $\mathrm{F}$ & 50 & $8 \mathrm{~h}$ & $\mathrm{E}$ & Morto & Deitado na cama & Intacto \\
\hline \multicolumn{9}{|l|}{ THYSANURA (silverfish) } \\
\hline $\begin{array}{l}\text { Btenolepisma longicaudata (46) } \\
\text { ARANEAE (aranhas) }\end{array}$ & Bangu & $\mathrm{F}$ & 30 & $20 \mathrm{~h}$ & E & Vivo & Deitado na cama & Intacto \\
\hline Gnaphosidae (07) & Estácio & M & 44 & $1 \mathrm{~h}$ & D & Morto & Deitado na cama & Intacto \\
\hline Plexippus paykulli (45) & Engenho Novo & $\mathrm{F}$ & 19 & $4 \mathrm{~h}$ & E & Morto & Dormindo na cama & Intacto \\
\hline
\end{tabular}


Quase todos os dípteros encontrados pertencem ao gênero Cochliomyia Townsend (25\%), gênero endêmico no Novo Mundo. A maioria (54\%) era C.hominivorax (Coquerel) (Figura 4) e somente 7,7\% era C.macellaria (Fabricius). Ambas as espécies foram coletadas no estágio larval; pertencem à família Calliphoridae, sendo duas das mais abundantes e disseminadas espécies deste gênero. As larvas são parasitas obrigatórios, causando miíase em homens e outros animais; normalmente desenvolvendo-se na derme e sub-derme. C.hominivorax tem sua distribuição do sul dos EUA até o norte do Chile, Argentina e Uruguai. Trata-se de um parasita obrigatório de feridas em mamíferos, requerendo tecidos vivos como alimento e infestando quase todas as formas de animais domésticos, selvagens e seres humanos (Guimarães e Papavero, 1999). C.macellaria é comum em regiões tropicais e subtropicais do hemisfério ocidental. Podem atuar como invasores secundários de feridas. Um dos casos de C.hominivorax ocorreu em ambas as fossas nasais de um mendigo.

Os outros dípteros são 4 mosquitos da família Culicidae e 1 mosca da família Sarcophagidae, Oxysarcodexia amorosa (Townsend). Os membros da família Sarcophagidae são, sem exceção, vivíparos ou ovovivíparos. As larvas desenvolvem-se em carcaças, excrementos ou material orgânico em decomposição. Machos são freqüentes visitantes de flores, mas as fêmeas de algumas espécies são parasitas de outros invertebrados, algumas vezes destruindo os ovos ou larvas do hospedeiro (Shewell, 1987). Casos de miíase acidental por larvas de sarcofagídeos têm sido relatados, incluindo um caso de miíase auricular causado porBercaea haemorrhoidalis(Fallén) na Argentina (Guimarães \& Papavero, 1999).

Os coleópteros (Figuras 5-6) recolhidos pertencem à família Scarabaeidae, que incluem espécies fitófagas, facilmente atraídas pela luz de mercúrio. São aqui representados pelas subfamílias Rutelinae (60\%) e Dynastinae (40\%). Leu cothereus spp. representam 40\% dos besouros invasores. Os lepidópteros, uma das maiores ordens de insetos, predominantemente fitófagos, são aqui representados por 7 famílias (Nielsen \& Common,1991).

Dos hemípteros coletados, 25\% são Macyconalia cavifrons (Stal), 25\% Cicadellidae, 25\% Cydnidae e 25\% Cimex hemipterus (Fabricius). Este último, juntamente com outras espécies do mesmo gênero, é conhecido como percevejo de cama comum. São parasitas tropicais de aves e mamíferos, mas atacam o homem com freqüência, para sugar seu sangue. O Cimex hemipterus vive nas residências, próximo aos leitos dos seres humanos, saindo à noite para alimentar-se, o que faz rapidamente, tornando-se ingurgitado em poucos minutos. Produz, caracteristicamente, vários pontos de picadas, separados por pequena distância, em um arranjo linear. Normalmente, as picadas não são sentidas, nem há preferência por nenhum local específico (embora a face seja o local mais atingido, já que mais freqüentemente encontra-se descoberta durante o sono). Algumas pessoas são assintomáticas, mas edema e prurido podem ocorrer (Waterhouse, 1991).

Os himenópteros foram o grupo de insetos menos representado $(5,35 \%)$. A maioria dos espécimes coletados foi das famílias Formicidae (formigas-66,60\%) e Apidae (abelhas-33,40\%). Ambas são sinantrópicas (espécies que se adaptaram bem às condições criadas pelo homem, mantendo uma dependência, e possuindo grande adaptação ao ambiente urbanizado), e muito comuns em áreas urbanas.

Os isópteros (cupins) foram representados por 2 amostras de Coptotermes hevilandi (Horlmargren). Trata-se de uma Ordem relativamente pequena, próxima aos Blattodea, e ocorrem predominantemente em regiões tropicais e subtropicais. Estes insetos alimentam-se de madeira, sadia ou não, grama seca, fungos e outros materiais de origem vegetal. O principal material usado é a celulose, mas algumas espécies são capazes de degradar a lignina (Watson \& Gay, 1991).

A pequena e cosmopolita ordem dos Thysanura é representada por uma amostra de Btenolepisma longicaudata (Escherich). A maioria dos Thysanura é de vida livre e são extremamente ágeis. São hominívoros e muito pequenos, medindo de 3 a $7 \mathrm{~mm}$ de comprimento (Smith \& Watson, 1991).

A Ordem Araneae é representada pelas famílias Gnaphosidae, que vive somente no solo, raramente em contato com o homem, e Salticidae, que é sinantrópica. Plexippus paykulli (Audoin) é conhecida como "eat-fly", já que se movimenta muito para obter comida, uma vez que não tecem teia. São domésticas e muito comuns.

Os Embioptera e Psocoptera (representados por 1,8\% cada) são insetos sem importância médica. Embioptera é uma das menores e menos estudadas Ordens de insetos, sendo essencialmente tropicais e alimentando-se exclusivamente de vegetais. Os Psocoptera são encontrados em todas as regiões zoogeográficas, nas folhagens, galhos, casca de árvores, sob pedras, em cavernas, em habitações humanas e em produtos estocados. (Smithers, 1991).

\section{Aspectos Clínicos}

Com relação ao sexo, não houve diferença significativa, sendo $51,79 \%$ do sexo feminino e $48,21 \%$ do sexo masculino.

Dentre as faixas etárias, $25 \%$ estavam na faixa de 0 a 12 anos, $12,5 \%$ entre 13 e 21 anos, 58,92\% entre 22 e 59 anos e somente $1,78 \%$ acima dos 60 anos. O caso em criança menor foi miíase auricular em uma criança de 1 ano de idade.

O tempo médio decorrido entre a entrada do invasor e sua remoção foi de cerca de 9 horas, sendo o mais rápido o de uma barata em morador do Centro (próximo ao hospital), que levou cerca de meia hora, e o mais demorado um outro caso de barata em um paciente de 59 anos de Campo Grande (subúrbio da zona Oeste do Rio), que levou cerca de 7 dias para procurar o serviço. Houve 4 casos em que a 


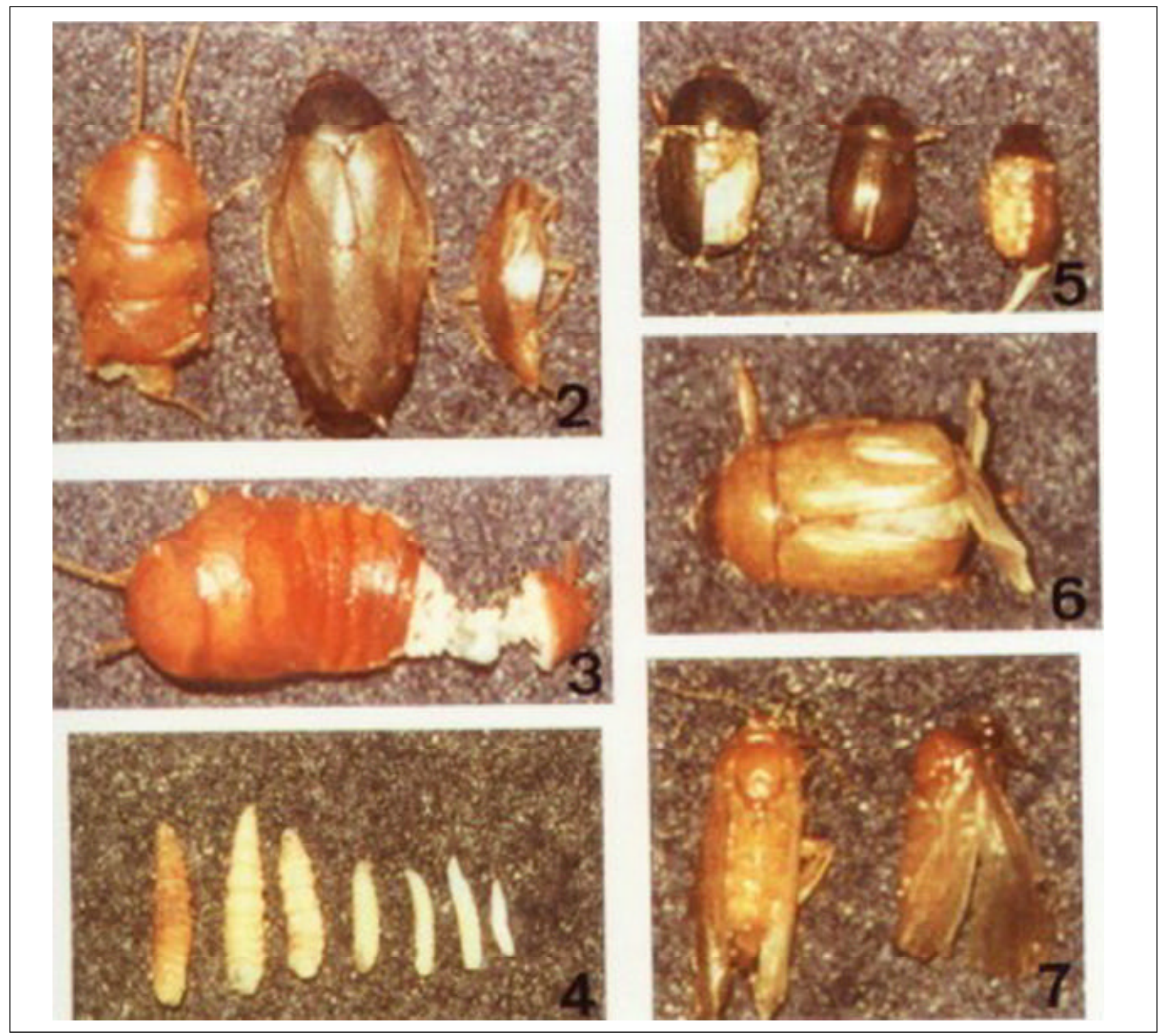

Figura 2. (esquerda para direita): Periplaneta sp (amostra 58); Pycnoscelus surinamensis (amostra 56); Blatella germanica (amostra 17). Figura 3. Ischnoptera sp (amostra 50). Figura 4. Larvas de Cocchliomyia hominivorax (várias amostras). Figura 5. (esquerda para direita): Eutheola humilis (amostra 53); Leucothyreus sp (amostra 26); Leucothyreus sp (amostra 08). Figura 6. Geniates sp (amostra 4 ). Figura 7. (esquerda para direita): Ardiosterus sp (amostra 51); Noctuidae (amostra 11).

pessoa ignorava o momento da invasão, 2 casos de míiase, 1 de mosquito (Culex sp.) e 1 de abelha (Apidae). Normalmente, as pessoas percorrem 2 ou mais hospitais antes de chegar ao Souza Aguiar, devido à grande deficiência de atendimento em ORL no Estado do Rio de Janeiro, e ao fato do Hospital Souza Aguiar ser referência para corpos estranhos em ORL.

Com relação ao local da invasão, 51,79\% ocorreu no ouvido direito, 46,42\% no ouvido esquerdo e 1 caso de mirase nasal $(1,79 \%)$.

Quanto ao estado do invasor, 73,22\% encontravamse mortos no momento da remoção e $26,78 \%$ vivos. Dentre os vivos, os mais freqüentes foram Diptera $(53,33 \%$, sendo $75 \%$ deste total miíase), Blattaria (26,66\%), Hemiptera, Lepidoptera e Thysanura (6,66\% cada). Dentre as atividades exercidas pelas pessoas no momento da invasão, vale

Revista Brasileira de Otorrinolaringologia 68 (5) Parte 1 Setembro/Outubro 2002 http://www.sborl.org.br / e-mail: revista@sborl.org.br 


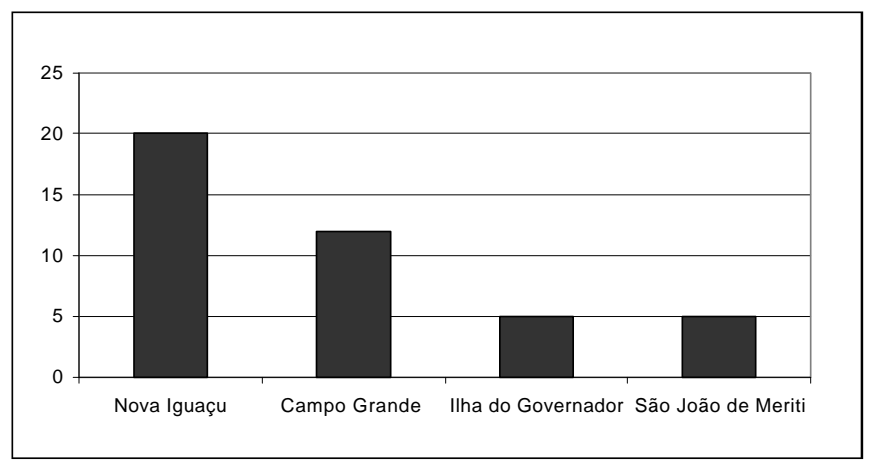

Figura 8. Áreas onde a maioria dos casos foi registrada (\%)

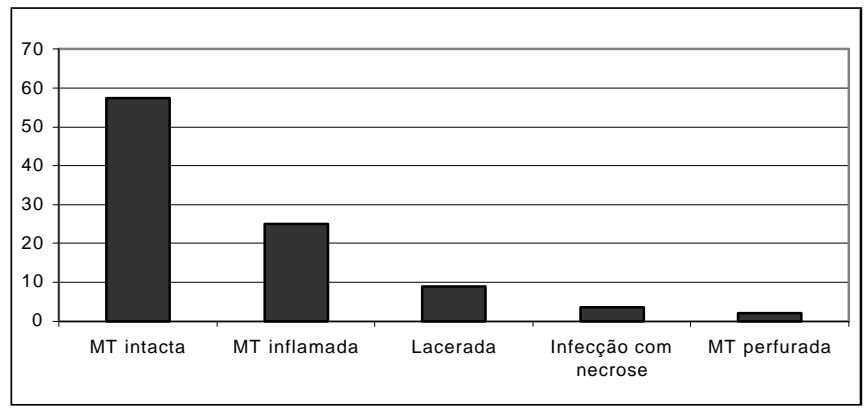

Figura 9. Estado do canal auditivo (\%) (MT = membrana timpânica)

ressaltar que $23,21 \%$ estavam deitadas na cama, $16,07 \%$ deitadas no chão e 7,14\% próximas a áreas de vegetação abundante ou árvores. Portanto, os fatores imobilidade e decúbito, além da proximidade a áreas verdes mostraramse relevantes para a invasão.

As regiões da Baixada Fluminense (Nova Iguaçu) e Zona Oeste (Campo Grande) respondem pela maioria dos casos (Figura 8).

Em cerca de 58\% dos casos não houve complicações; porém, quando presentes, as mais freqüentes foram hiperemia do conduto auditivo externo, laceração do conduto auditivo externo, infecção secundária e necrose da orelha externa e perfuração timpânica (Figura 9). As complicações foram, em sua maioria, de pouca gravidade e tratadas com medicação tópica (gotas otológicas) e sintomáticos. Em caso de perfuração timpânica, foram prescritos antibióticos e feito o acompanhamento ambulatorial. A maioria dos casos graves consistiu em mí́ase, causada principalmente por larvas de C.hominivorax. No caso de míase auricular, realizou-se a remoção do maior número possível de larvas, preferencialmente sob visão micros- cópica. Fez-se curativo ocluindo a luz do CAE (o que reduz o suprimento de ar para as larvas) e utilizando-se o calomelano, derivado mercurial que, apesar de vários relatos quanto a possível neuro e hepato-toxicidade, tem se mostrado totalmente seguro para uso em ORL, conforme experiência do serviço. A nosso ver, a miíase auricular é perfeitamente tratável a nível ambulatorial, a não ser que razões de ordem social impeçam. Realizamos curativos em dias alternados, com prescrição de antibióticos (cefalexina), até a normalização do quadro. Em nenhum dos casos verificamos seqüelas, exceto naqueles que já possuíam patologia inflamatória crônica, tais como otite média e sinusopatia. Crianças com otite média crônica são alvos freqüentes, devido às más condições sócio-econômicas.

O caso mais grave certamente foi o de um mendigo com miíase nasal, que apresentava supuração, necrose de cartilagem septal e de cornetos inferiores. Miíase nasal é comum em pacientes idosos, psiquiátricos, alcoólatras e portadores de granulomatoses nasais, particularmente naqueles que habitam regiões rurais. Além disso, as freqüentes quedas, associadas à pouca mobilidade, provocam sangramentos que atraem algumas espécies de moscas. Nesses casos, é necessária a internação do paciente para antibioticoterapia parenteral e debridamento cirúrgico das lesões, mas as seqüelas são muito freqüentes, com largas perfurações septais. Não temos experiência com o uso de ivermectina, anti-parasitário mencionado por Ramalho et al. (2001).

\section{CONCLUSÃO}

Não são incomuns os casos de invasão de orelha, nariz e garganta por insetos e outros organismos. A maioria dos casos resolve-se facilmente e sem seqüelas, mas alguns podem evoluir para graves complicações. A maioria dos insetos coletada neste estudo é atraída pela luz de mercúrio e restos de comida. Portanto, uma forma de minimizar a invasão de cavidades humanas por insetos é reduzir o uso de luz de mercúrio e medidas de limpeza e higiene, eliminando, por exemplo, os restos de comida. Também é importante, no sentido de evitar-se complicações, a não tentativa de remoção por profissional não habilitado ou na falta de material adequado.

\section{AGRADECIMENTOS}

Aos pesquisadores dos Departamentos de Entomologia e Invertebrados do Museu Nacional, UFRJ - Sonia Maria Lopes Fraga, Paulo Magno, Gabriel Mejdalani, Renner Luiz Cerqueira Baptista, Denise Pamplona e Maria Antonieta Pereira de Azevedo, pelo auxílio na identificação do material, e a todos os otorrinolaringologistas do Hospital Municipal Souza Aguiar. 


\section{REFERÊNCIASBIBUOGRÁFICAS}

1. Costa Lima AM. Insetos do Brasil. 1o Tomo - Série didática, no 2 da Escola Nacional de Agronomia do Rio de Janeiro; 1938. p. 1-470.

2. Guimarães JH \& Papavero N. Myiasis in man and animals in the neotropical region; Bibliographic database. São Paulo: Editora Plêiade/Fapesp; 1999. p.1-308.

3. Nielsen ES \& Common IFB. Lepidoptera: 817-915. In: The Insects of Australia. A textbook for students and research workers. Volume II, Second Edition, Division of Entomology CSIRO Australia; 1991. p. 543-1132.

4. Ramalho JRO et al. Míase nasal: relato de um caso. Revista Brasileira de Otorrinolaringologia 2001;67(4):581-4.

5. Ross ES. Embioptera (Embiidina): 400-5. In: The Insects of Australia - A textbook for students and research workers. Volume I, Second Edition, Division of Entomology CSIRO Australia; 1991. p.1-542.
6. Shewell GE. Sarcophagidae: 1159-86. In: Manual of the Nearctic Diptera Vol. II. Otawa, Agriculture Canada, Research Branch Monograph, 28, 1987. vi + 675-1332 p.

7. Smith GB \& Watson JA. Thysanura (Zygentoma): 275-8. In: The Insects of Australia. A textbook for students and research workers. Volume I, Second Edition, Division of Entomology CSIRO Australia; 1991. p.1-542.

8. Smithers CN. Psocoptera: 412-20. In: The Insects of Australia. A textbook for students and research workers. Volume I, Second Edition, Division of Entomology CSIRO Australia; 1991. p.1-542.

9. Waterhouse DF. Insects and humans in Australia: 221-35. In: The Insects of Australia. A textbook for students and research workers. Volume I, Second Edition, Division of Entomology CSIRO Australia; 1991. p.1-542.

10. Watson JAL \& Gay FJ. Isoptera: 330-47. In: The Insects of Australia A textbook for students and research workers. Volume I, Second Edition, Division of Entomology CSIRO Australia; 1991 p.1-542. 